\title{
Electrostatic effects on nanofiber formation of self-assembling peptide amphiphiles
}

\author{
Sila Toksoz ${ }^{1}$, Rashad Mammadov ${ }^{1}$, Ayse B. Tekinay, Mustafa O. Guler * \\ UNAM-Institute of Materials Science and Nanotechnology, Bilkent University, Ankara 06800, Turkey
}

\section{A R T I C L E I N F O}

\section{Article history:}

Received 13 November 2010

Accepted 27 December 2010

Available online 1 January 2011

\section{Keywords:}

Self-assembly

Nanofiber

Peptide

Gel

Peptide amphiphile

Electrostatic interactions

\begin{abstract}
A B S T R A C T
Self-assembling peptide amphiphile molecules have been of interest to various tissue engineering studies. These molecules self-assemble into nanofibers which organize into three-dimensional networks to form hydrocolloid systems mimicking the extracellular matrix. The formation of nanofibers is affected by the electrostatic interactions among the peptides. In this work, we studied the effect of charged groups on the peptides on nanofiber formation. The self-assembly process was studied by $\mathrm{pH}$ and zeta potential measurements, FT-IR, circular dichroism, rheology, atomic force microscopy, scanning electron microscopy and transmission electron microscopy. The aggregation of the peptides was triggered upon neutralization of the charged residues by $\mathrm{pH}$ change or addition of electrolyte or biomacromolecules. Understanding the controlled formation of the hydrocolloid gels composed of peptide amphiphile nanofibers can lead us to develop in situ gel forming bioactive collagen mimetic nanofibers for various tissue engineering studies including bioactive surface coatings.
\end{abstract}

(c) 2010 Elsevier Inc. All rights reserved.

\section{Introduction}

Extracellular matrix (ECM) is an elastic network of locally secreted proteins and proteoglycans, which surrounds and supports cells while providing adhesion sites. Complex biological processes such as development, wound healing, immune response, and physiological functions are partly controlled by cell adhesion to ECM proteins [1]. It is of extreme importance for synthetic scaffolds to mimic the ECM to have control over cell attachment, proliferation and differentiation for tissue engineering purposes. Collagen is one of the most widely mimicked materials as an artificial ECM [2]. Providing the structural and organizational framework for cartilage, bone, tendon, blood vessels, skin, and fascia, collagen constitutes the main structural component of the connective tissue [3] and plays an important role in promoting cell adhesion while mediating intracellular signals critical to tissue function [4,5]. Collagen and its mimics have been used in numerous medical applications ranging from hemostatic materials [6] and biocompatible coatings [7] to drug delivery [8] and tissue engineering [9]. The characteristics of collagen are distinct from other natural polymers and their synthetic analogs that are used as biomaterials in terms of retaining cell binding and signaling properties, promoting cell differentiation, enhancement of tissue regeneration, having high tensile strength, low antigenicity, activation of platelets, and the capability of being produced in various shapes [10,11]. However, the use of collagen has been limited due to health concerns regard-

\footnotetext{
* Corresponding author. Fax: +90 3122664365.

E-mail address: moguler@unam.bilkent.edu.tr (M.O. Guler).

${ }^{1}$ Contributed equally to this work.
}

ing the native source of proteins, such as contamination with viruses and prions. Therefore, synthetic scaffolds mimicking natural collagen with enhanced biological functions have been developed $[12,13]$.

Various architectures have been designed to meet the physical and chemical norms of tissue at nanoscale. The invention of nanofibers has greatly improved the scope of fabrication of scaffolds and biomaterials with desired properties due to their high surface area to volume ratio and highly porous structure [14]. To date, three synthesis methods, namely self-assembly, phase separation and electrospinning, have evolved to allow the fabrication of fibrous nanostructures [14]. The self-assembling molecules produce nanofibers that are more analogous to collagen nanostructures in terms of size compared to the electrospinning and phase separation techniques [14]. The self-assembly process organizes molecules into ordered nanostructures through noncovalent interactions, where the final structural features can be tuned by environmental factors, such as temperature [15], pH [16], solvents [17], salts [18], and co-assembling molecules [19].

Self-assembling peptide amphiphile nanofibers have been widely used for various regenerative medicine applications. The peptide amphiphile (PA) molecules consist of a hydrophobic alkyl tail and a hydrophilic peptide molecule, which together make the molecule amphiphilic. These molecules self-assemble into nanofibers due to their amphiphilic character, where the hydrophobic part is stacked inside and the hydrophilic part is presented to outside in aqueous environment. The PAs have been used in applications ranging from bone formation through biomineralization [20], spinal cord injury by employing the IKVAV epitope in the head group to promote neurite growth [21] and differentiation of 
progenitor cells into neurons [22], the promotion of angiogenesis by self-assembly in the presence of heparin and capturing the growth factors taking part in the growth of the blood vessels [23], dental regeneration by displaying the RGD sequence and forming scaffolds for dental stem cells [24] to therapeutic delivery of bone marrow derived stem and progenitor cells by displaying the RGDS epitope [25].

In this study, we analyzed the effects of charged groups on the PA molecules on the self-assembly process. The self-assembly of PA molecules was triggered by charge screening through $\mathrm{pH}$ change or employment of oppositely-charged molecules like DNA and heparin, or ions, including calcium. Calcium was selected as a model ion due to its importance in biological applications. The stability and the charge of the molecules were assessed by zeta potential measurements and neutralization behaviors $\left(\mathrm{p} K_{\mathrm{a}}\right)$ of the PA molecules were assessed by acid-base titration. Various imaging techniques further helped to characterize the self-assembled nanostructures. Secondary structures and mechanical properties of the PA molecules were determined by CD and FT-IR, and rheological studies, respectively. Understanding self-assembly principles of PA molecules will enable researchers to tailor PA based materials to customize the self-assembly conditions and produce materials suitable for specific applications in terms of mechanical and cellinteraction properties. Knowledge about how the charge screening affects the self-assembly of peptides aid in understanding the forces acting in the self-assembly process of more complex structures like proteins upon interactions with salts, ions and macromolecules in vitro and in vivo.

\section{Experimental}

\subsection{Materials}

9-Fluorenylmethoxycarbonyl (Fmoc) and tert-butoxycarbonyl (Boc) protected amino acids, [4-[ $\alpha$ - $\left(2^{\prime}, 4^{\prime}\right.$-dimethoxyphenyl)Fmocaminomethyl]phenoxy]acetamidonorleucyl-MBHA resin (Rink amide MBHA resin), Fmoc-Asp(OtBu)-Wang resin and 2-(1H-benzotriazol-1-yl)-1,1,3,3-tetramethyluronium hexafluorophosphate (HBTU) were purchased from NovaBiochem and ABCR. Heparin was purchased from Sigma-Aldrich. Sheared Salmon Sperm DNA was purchased from Ambion. The other chemicals were purchased from Fisher, Merck, Alfa Aesar or Aldrich. All chemicals were used as provided.

\subsection{Peptide synthesis}

Peptides were constructed on Rink Amide MBHA resin or FmocAsp $(\mathrm{OtBu})$-Wang resin. Amino acid couplings were done with 2 equivalents of Fmoc protected amino acid, 1.95 equivalents HBTU and 3 equivalents of $\mathrm{N}, \mathrm{N}$-diisopropylethylamine (DIEA) for $2 \mathrm{~h}$. Fmoc removal was performed with 20\% Piperidine/Dimethylformamide (DMF) solution for $20 \mathrm{~min}$. Cleavage of the peptides from the resin was carried out with a mixture of TFA:TIS: $\mathrm{H}_{2} \mathrm{O}$ in ratio of 95:2.5:2.5 for $2 \mathrm{~h}$. Excess TFA was removed by rotary evaporation. The remaining viscous peptide solution was triturated with icecold ether and the resulting white product was dried under vacuum. Peptide amphiphiles were characterized by liquid chromatography-mass spectrometry (LC-MS). Mass spectrum was obtained with Agilent LC-MS equipped with Agilent Zorbax ExtendC18 $2.1 \times 50 \mathrm{~mm}$ column for basic conditions and Zorbax SB-C8 $4.6 \mathrm{~mm} \times 100 \mathrm{~mm}$ column for acidic conditions. A gradient of (a) water $\left(0.1 \%\right.$ formic acid or $\left.0.1 \% \mathrm{NH}_{4} \mathrm{OH}\right)$ and (b) acetonitrile $(0.1 \%$ formic acid or $0.1 \% \mathrm{NH}_{4} \mathrm{OH}$ ) was used. Agilent preparative reverse-phase HPLC system equipped with Zorbax Extend-C18 $21.2 \times 150 \mathrm{~mm}$ column for basic conditions and Zorbax SB-C8
$21.2 \times 150 \mathrm{~mm}$ column for acidic conditions was used to purify the peptides. A gradient of (a) water $\left(0.1 \%\right.$ TFA or $\left.0.1 \% \mathrm{NH}_{4} \mathrm{OH}\right)$ and (b) acetonitrile $\left(0.1 \%\right.$ TFA or $\left.0.1 \% \mathrm{NH}_{4} \mathrm{OH}\right)$ was used.

\subsection{FT-IR}

One milligram of $1 \mathrm{wt} \%$ lyophilized PA gel was grinded with $99 \mathrm{mg} \mathrm{KBr}$ until very fine powders were obtained. The finely ground mixtures were sandwiched between two stainless steel disks and hydraulic press was applied up to 7 atm. The FT-IR measurement was performed with Bruker Tenson 27 FT-IR spectrometer at the transmittance mode. The background spectrum was subtracted from the original spectrum.

\subsection{Circular dichroism}

JASCO J815 CD spectrapolarimeter was used at room temperature. $2 \times 10^{-4} \mathrm{M}$ peptide solutions were measured from $300 \mathrm{~nm}$ to $190 \mathrm{~nm}$, data interval and data pitch being $0.1 \mathrm{~nm}$, scanning speed being $100 \mathrm{~nm} / \mathrm{min}$, all measurements with three accumulations. DIT was selected as $1 \mathrm{~s}$, band width as $1 \mathrm{~nm}$, and the sensitivity was standard.

\subsection{Oscillatory rheology}

Oscillatory rheology measurements were performed with Anton Paar Physica RM301 Rheometer operating with a $25 \mathrm{~mm}$ parallel plate configuration at $25^{\circ} \mathrm{C}$. Each sample of $100 \mu \mathrm{L}$ total volume with a final peptide concentration of $1 \mathrm{wt} \%$ was carefully loaded on the center of the lower plate and incubated for $15 \mathrm{~min}$ before measuring. After equilibration, the upper plate was lowered to a gap distance of $0.5 \mathrm{~mm}$. Storage moduli $\left(G^{\prime}\right)$ and loss moduli $\left(G^{\prime \prime}\right)$ values were scanned from $100 \mathrm{rad} / \mathrm{s}$ to $0.1 \mathrm{rad} / \mathrm{s}$ of angular frequency, with a $0.5 \%$ shear strain.

\subsection{Zeta potential and $\mathrm{pH}$ titration}

Zeta potential measurements were performed with Malvern Nano-ZS Zetasizer equipped with a titrator and $\mathrm{pH}$ meter for $0.06 \mathrm{wt} \%$ PA solutions. Smoluchovski approach was used to calculate the Zeta Potential values. The $\mathrm{pH}$ titration was performed by adding $0.1 \mathrm{M} \mathrm{HCl}$ or $\mathrm{NaOH}$ to the appropriate solutions. The $\mathrm{p} K_{\mathrm{a}}$ values were also estimated by using MarvinSketch program.

\subsection{Atomic force microscopy (AFM)}

The AFM samples were prepared by mixing $25 \mu \mathrm{L}$ of PA solution of 0.025 or $0.075 \mathrm{wt} \%$ final concentrations with oppositely charged peptides, biomacromolecules or ions on a silicon wafer that had been cleaned with ethanol and dried at room temperature. DNA and heparin were mixed with Lys-PA in a $1: 3$ ratio $(0.025 \%$ DNA/ Heparin with $0.075 \%$ Lys-PA). Asp-PA (0.025 wt\%) and Lys-PA $(0.025 \mathrm{wt} \%)$ were mixed in a $1: 2$ mole ratio. Asp-PA was mixed with calcium ions $\left(\mathrm{CaCl}_{2}\right)$ in a 1:2 mole ratio. Sample solutions were dropped on the silicon wafer surface and mixed by pipetting up and down. After $30 \mathrm{~s}$, solvent on the wafer was removed by using dust-free tissue paper and the rest was air-dried. Contact mode atomic force microscopy (AFM) was performed by using model MFP-30 from Asylum Research. All images were taken with $0.5 \mathrm{~Hz}$ scan rate. Tips with resonance frequency of $13 \mathrm{kHz}$ and spring constant of $0.2 \mathrm{~N} / \mathrm{m}$ were used in all experiments.

\subsection{Scanning electron microscopy (SEM)}

One hundred microliters of PA gels with a final concentration of $1 \mathrm{wt} \%$ were placed on a metal mesh, dried at critical point (1072 
Psi, $31^{\circ} \mathrm{C}$ ) with Tousimis Autosamdri-815 B, Series C critical point dryer and coated with $6 \mathrm{~nm}$ Au-Pd. SEM imaging was performed with FEI Quanta 200 FEG, using the ETD detector at high vacuum mode with $30 \mathrm{keV}$ beam energy. Cryo-SEM imaging was performed by using $1 \mathrm{wt} \%$ PA gels or solutions placed on cryo stage of the SEM. 1 wt\% Lys-PA was mixed either with DNA (0.33\%), or heparin $(0.33 \%)$ or $1 \mathrm{M} \mathrm{NaOH}$ solution to induce gel. $1 \mathrm{wt} \%$ Asp-PA was mixed either with $1 \mathrm{M} \mathrm{CaCl}_{2}$ or $1 \mathrm{M} \mathrm{HCl}$ or $1 \mathrm{wt} \%$ Lys-PA for the same purpose. $1 \mathrm{wt} \%$ His-PA was mixed with $1 \mathrm{M} \mathrm{NaOH}$ to shift the $\mathrm{pH}$ to 7 for gel formation. SEM imaging was performed with FEI Quanta 200 FEG, using the GSED detector at ESEM mode with 10-15 keV beam energy.

\subsection{Transmission electron microscopy (TEM)}

TEM was performed with FEI Tecnai G2 F30. Diluted samples were placed on a Lacey mesh ultrathin carbon coated copper grid. $2 \mathrm{wt} \%$ uranyl acetate solution or phosphotungstic acid solutions were used for positive and negative staining, respectively. The grid was placed on $1 \mathrm{wt} \%$ PA gel upside down for $1 \mathrm{~min}$. Then, the grid was washed to remove excess coating and was put over the staining solution for $15 \mathrm{~min}$. After the staining, the grids were dried in the fume hood at room temperature overnight.

\section{Results and discussion}

In order to better understand the self-assembly mechanism of PA molecules, three molecules were designed and synthesized by solid phase peptide synthesis method and mixed with various biomolecules and oppositely charged ions to explore the effect of electrostatic interactions on nanofiber formation (Fig. 1). The lauric acid adds hydrophobic character to the PA structure, contributing to the hydrophobic driving force of the self-assembly. The peptide part consists of four nonpolar amino acid residues, forming the $\beta$ sheet module, and a charged amino acid, for solubility and charge control. Lys-PA (Lauryl-VVAGK-Am) was designed to have a lysine residue and since it is positively charged at acidic conditions, it forms gels upon increasing the $\mathrm{pH}$ by mixing with negatively charged macromolecules (e.g. heparin, DNA), or by addition of Asp-PA (Lauryl-VVAGD), a negatively charged PA at neutral conditions. His-PA (Lauryl-VVAGH-Am) was designed with a histidine residue making it soluble in acidic solutions and gel above $\mathrm{pH}$ 6.5. The Asp-PA (Lauryl-VVAGD) is a negatively charged PA at neutral and basic conditions and formed gels at low $\mathrm{pH}$ conditions as well as in the presence of calcium ions or positively charged molecules at neutral $\mathrm{pH}$.

The effect of neutralization of charges on the self-assembly of the PA molecules was studied by zeta potential measurements (Fig. 2) and $\mathrm{pH}$ titration curves to determine the $\mathrm{p} K_{\mathrm{a}}$ transitions of ionizable groups at the self-assembly conditions (Fig. 3). The ionizable group of the Lys-PA is the $\varepsilon$-amine of lysine. The neutralization $\mathrm{pH}$ of the Lys-PA solution was measured around $\mathrm{pH} 7-8$ (Fig. 3a). The $\mathrm{p} K_{\mathrm{a}}$ value of the Lys-PA was observed to be lower than the literature value for the lysine amino acid which is caused by aggregation of the PA molecules. The $\mathrm{p} K_{\mathrm{a}}$ values of lysine residue in dendritic poly-L-Lysine were found to be lower than the lysine amino acid's $\mathrm{p} K_{\mathrm{a}}$ because of the aggregation of the molecules [26]. The His-PA has an ionizable imidazole side chain and its neutralization was observed to be around pH 6 (Fig. 3b). The Asp-PA has two carboxylic acid groups at the C-terminal and the side chain, whose $\mathrm{p} K_{\mathrm{a}}$ transition values are 2.10 and 3.90 , respectively. We observed that the $\mathrm{p} K_{\mathrm{a}}$ values of the carboxyl groups shifted compared to aspartic acid residue itself (Fig. 3c). In the literature, such shifts have also been observed in other peptide amphiphiles $[27,28]$. Molecules were theoretically titrated with MarvinSketch software as well, where the $\mathrm{p} K_{\mathrm{a}}$ value for Lys-PA is 10.21 ; for His$P A$, it is calculated as 6.80; and finally for Asp-PA, deprotonation at C-terminal occurs at 5.40, similar to the value obtained experimentally, and the side chain deprotonation occurs at $\mathrm{pH} 2.50$. The shifts might be attributed to aggregation [27] and hydrogen bonding [29]. Hydrogen bonds within and between the molecules are known to affect the $\mathrm{p} K_{\mathrm{a}}$ values. Most of the ionizable groups exhibit a complex titration behavior, which is most likely due to the local environment in the nanofibers. The Lys-PA and His-PA are both positively charged at $\mathrm{pH}<5$, whereas the Asp- $P A$ is negatively charged at $\mathrm{pH}>5$. The stability and the electrostatic charge of colloids can be verified by zeta potential measurements. Values above $+30 \mathrm{mV}$ or below $-30 \mathrm{mV}$ are considered to represent sufficient repulsion between molecules to ensure physical stability of the molecules while values between $+30 \mathrm{mV}$ and $-30 \mathrm{mV}$ indicate that<smiles>CCCCCCCCCCCC(=O)N[C@H](C(=O)N[C@H](C(=O)N[C@@H](C)C(=O)NCC(=O)N[C@@H](CCCCN)C(N)=O)C(C)C)C(C)C</smiles><smiles>CCCCCCCCCCCC(=O)N[C@H](C(=O)N[C@H](C(=O)N[C@@H](C)C(=O)NCC(=O)N[C@@H](Cc1c[nH]cn1)C(N)=O)C(C)C)C(C)C</smiles>

His-PA<smiles>CCCCCCCCCCCC(=O)N[C@H](C(=O)N[C@H](C(=O)N[C@@H](C)C(=O)NCC(=O)N[C@@H](CC(=O)O)C(=O)O)C(C)C)C(C)C</smiles>

Asp-PA

Fig. 1. Chemical representation of PAs. 
(a)
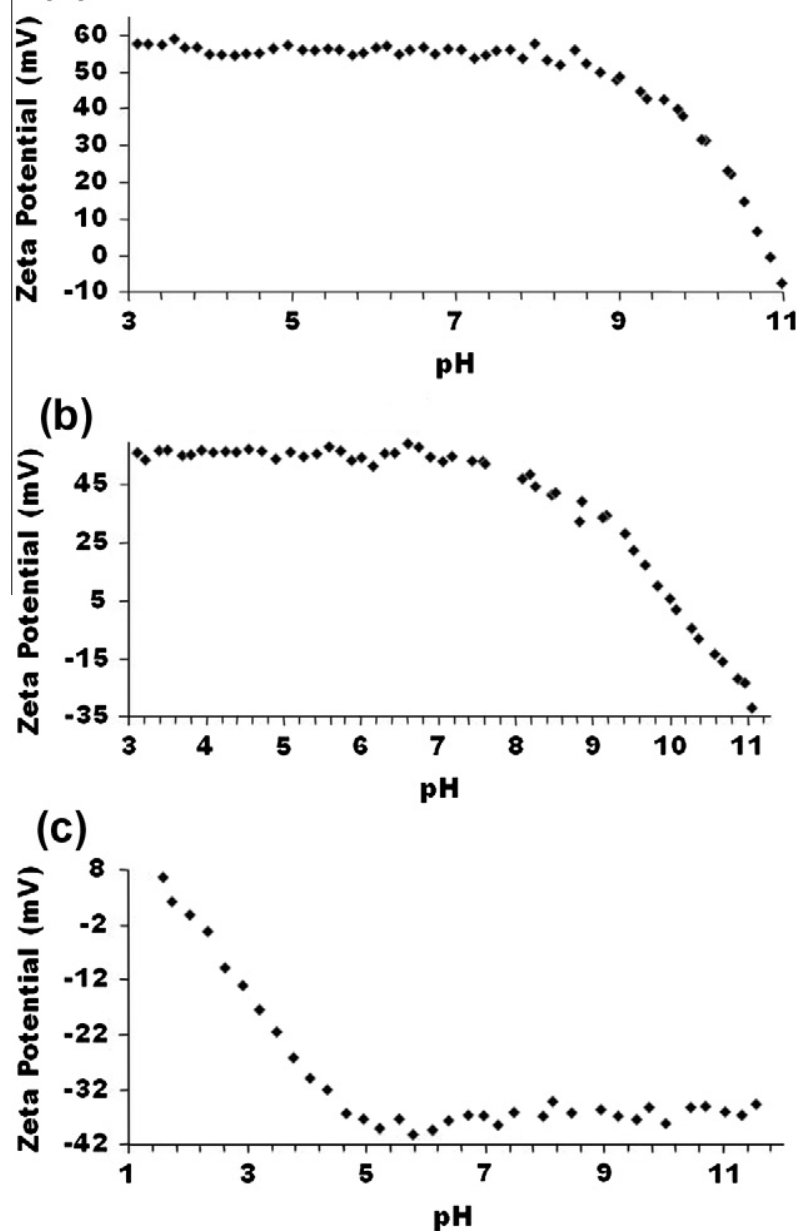

Fig. 2. The $\mathrm{pH}$ dependent Zeta Potential measurement of (a) Lys-PA titrated with $0.1 \mathrm{M} \mathrm{NaOH}$, (b) His-PA titrated with $0.1 \mathrm{M} \mathrm{NaOH}$, and (c) Asp-PA titrated with $0.1 \mathrm{M}$ $\mathrm{HCl}$.

the molecules are likely to coagulate. If the zeta potential is low, then there will be no force to prevent the flocculation of molecules. The zeta potential value of the Lys-PA solution decreases with increasing $\mathrm{pH}$ by adding alkali solution and it does not start to coagulate until a pH close to 10 as the charges are not fully neutralized. The Asp-PA solution becomes unstable below $\mathrm{pH} 4$, as there are not sufficient negative charges present to stay in the solution. For the His-PA solution, the zeta potential decreases above $\mathrm{pH} 7$ and becomes lower than $30 \mathrm{mV}$ above $\mathrm{pH}$ 9. These zeta potential and acid-base titration results are consistent with the nanofiber formation and gelation behaviors of the PA molecules.

The self-assembly of the PA molecules was also studied by various imaging techniques. The charged residues of the PAs interact with oppositely charged ions and molecules, and the PAs selfassemble into nanofibers with diameters of about $8 \mathrm{~nm}$ and lengths up to a few microns as revealed by TEM and AFM. For the Lys-PA samples, the charge screening of the $\varepsilon$-amine group by hydroxide ions (Fig. S7b and c), heparin (Fig. S8b and c), DNA (Fig. S9b and c) or the aspartate moiety of the Asp-PA (Fig. S10b and c) resulted in aggregation of the molecules, formation of nanofibers and a gel structure. The screening of the charges on the carboxyl groups of the Asp-PA by calcium ions (Fig. 4b and c) or hydronium ions (Fig. S11b and c) minimized the electrostatic repulsion among the head groups of the peptides, which caused aggregation and nanofiber formation. The imidazole side chain of histidine on the His-PA carries a positive charge at low $\mathrm{pH}$ but is neutralized at $\mathrm{pH}>7$
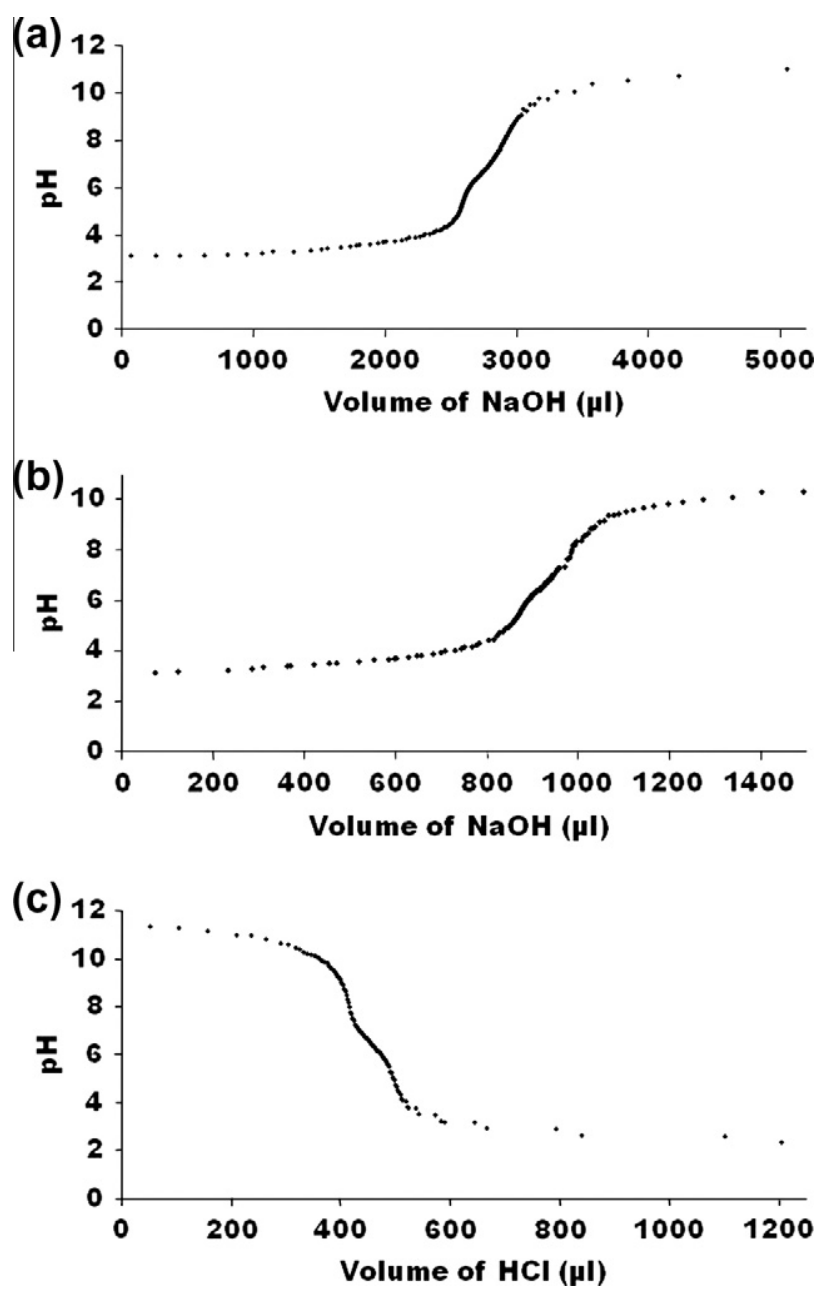

Fig. 3. $\mathrm{pH}$ titration curves of PAs. (a) Lys-PA titrated with $0.1 \mathrm{M} \mathrm{NaOH}$, (b) His-PA titrated with $0.1 \mathrm{M} \mathrm{NaOH}$, (c) Asp-PA titrated with $0.1 \mathrm{M} \mathrm{HCl}$.

and self-assembles into fibrillar nanostructures (Fig. S12). In some of the PA samples (data not shown), plaque structures along with nanofibers were observed. These structures might be caused by sample preparation, since the samples for imaging were prepared by dehydrating and drying in air, which might have resulted in the fusion of nanofibers [15] or it would be possible to see an intermediate step before the fiber formation.

AFM imaging revealed the formation of PA nanofibers depending on $\mathrm{pH}$ change ( $\mathrm{pH} 2$ for Asp-PA, $\mathrm{pH} 7$ for His-PA and $\mathrm{pH} 10$ for Lys-PA) or mixing with charged macromolecules (DNA or heparin with Lys-PA) and cations $\left(\mathrm{Ca}^{2+}\right.$ with Asp-PA). The Asp-PA with $\mathrm{Ca}^{2+}$ formed longer fibrils (Fig. 4) compared to other peptide amphiphiles (Figs. S7-S12). Calcium presumably acts as a connector between the carboxyl groups of the aspartate residues, as proposed in another study [30]. This might aid in the self-assembly process to produce stronger bonds and hence, longer fibrils (Fig. 4b). Three-dimensional network of the nanofibers were also observed by SEM (Figs. 4a, S7a-S12a). All of the molecules mentioned above were observed to form a nanofiber matrix upon isolation of the charges.

In addition, we performed cryo-SEM and AFM measurements by using PA solutions to understand the degree of aggregation in solution and effect of drying on the self-assembly process (Figs. S16-S18). The peptides revealed some degree of self-assembly in solution and upon drying as well. However, rheology measurements clearly demonstrates that neutralization of the ionized pep- 

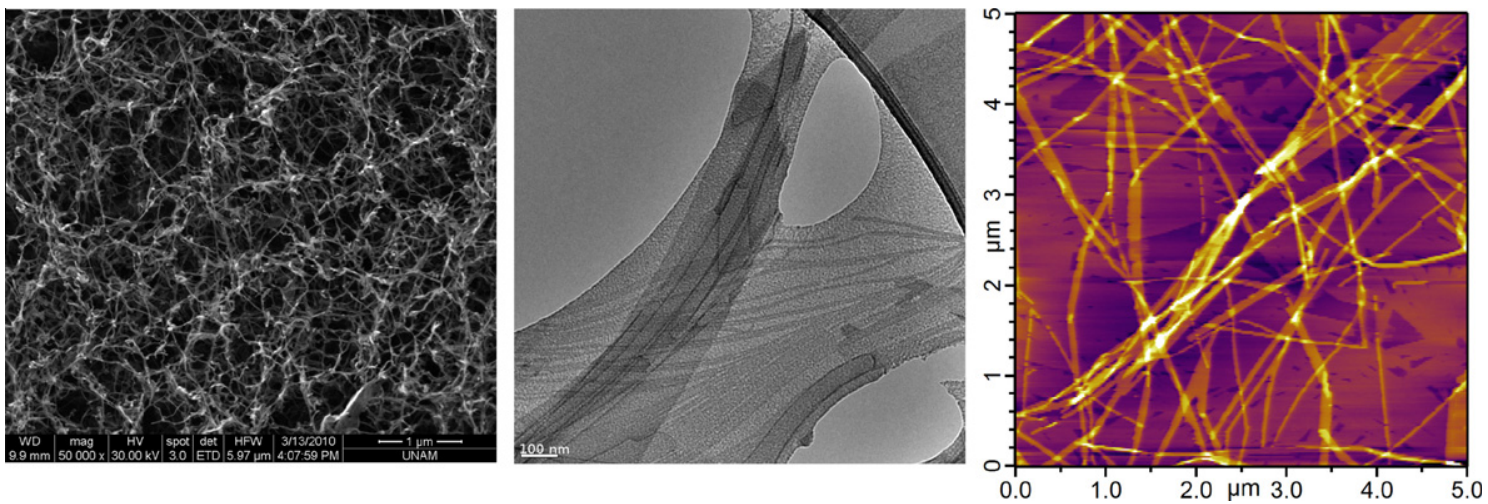

Fig. 4. SEM, TEM and AFM images of the Asp-PA with $\mathrm{Ca}^{2+}$

tides is necessary for self-supporting gel formation. Therefore, we believe that the neutralization of peptides enhances the extended nanostructure formation which results in encapsulation of water in a three-dimensional nanofiber network.

FT-IR measurements were performed to analyze the characteristic bands for hydrogen bonding between peptides (Fig. 5). The amide A band around $3300-3500 \mathrm{~cm}^{-1}$ and amide $\mathrm{B}$ band around $3100 \mathrm{~cm}^{-1}$ are due to a Fermi resonance of the NH stretching vibration and the first overtone of the amide II. Amide I band, observed between 1600 and $1700 \mathrm{~cm}^{-1}$, is associated with the carbonyl stretching vibrations of the peptide backbone. The peaks around $1650 \mathrm{~cm}^{-1}$ and $1693 \mathrm{~cm}^{-1}$ can be attributed to parallel and antiparallel $\beta$-sheets, respectively. In the absence of gelators, all three peptides exhibit some $\beta$-sheet structure. There are peaks around $1730 \mathrm{~cm}^{-1}$ in the Asp-PA at $\mathrm{pH} 2$, the Asp-PA with $\mathrm{Ca}^{2+}$, and the Lys-PA with Asp-PA with the strongest peak observed at $\mathrm{pH} 2$, the carbonyl stretching vibration of aspartate side chain is known to generate a peak around those values [31]. Asp-PA alone has a peak at $1730 \mathrm{~cm}^{-1}$ as well. Lysine side chain gives weak bands in infrared in neutralized state, making the bands difficult to assign. At $1228 \mathrm{~cm}^{-1}$, the asymmetric stretching of sulfate belonging to heparin is observed. No $\alpha$-helical structures were observed in the FT-IR.

Circular dichroism (CD) spectroscopy was also employed to understand the secondary structures and conformations of the PAs (Fig. 6). When the structure of a molecule is chiral, there is a difference in the absorbance of right-handed polarized light versus left-handed polarized light. The CD measures these absorbance differences, where the amide group forming the peptide backbone in regular environment acts as the chromophore in the far-UV region. The $\beta$-sheets display a negative minimum at $218 \mathrm{~nm}$ and a positive ellipticity at $195 \mathrm{~nm}$ [32]. The Lys-PA in solution has a secondary

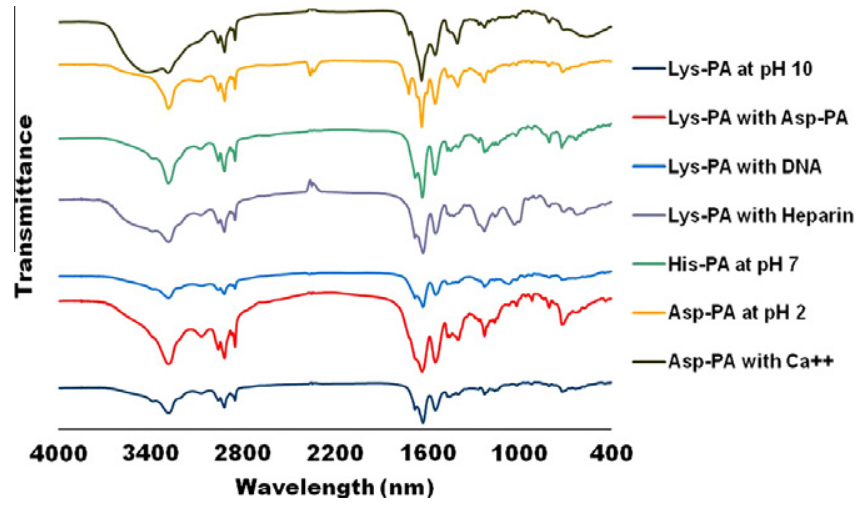

Fig. 5. FT-IR spectra of lyophilized PA gels.

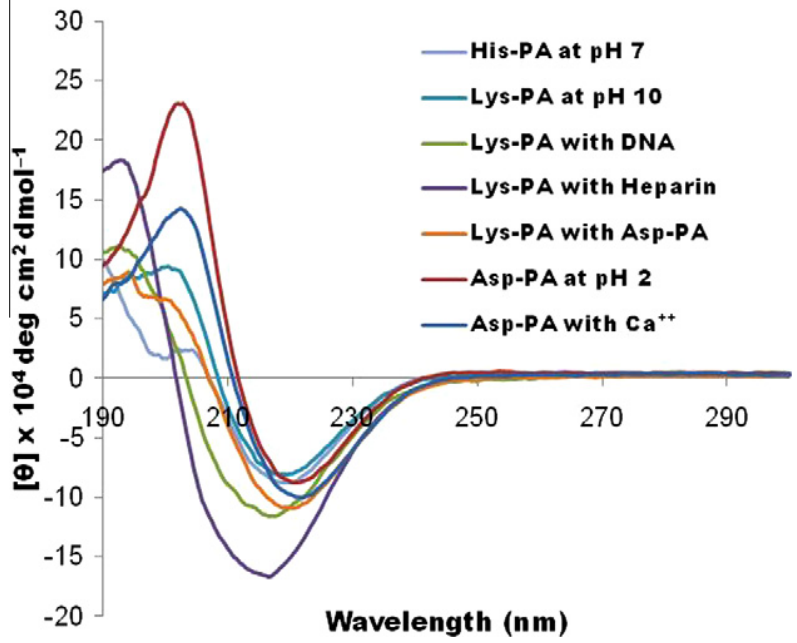

Fig. 6. CD spectra of the PA solutions.

structure of random coil and $\beta$-sheet. When mixed with DNA or heparin, it contains predominantly $\beta$-sheet structure. The reason why Lys-PA with heparin has a more intense band compared to other Lys-PA samples can be explained by the better cross-linking of peptide molecules, forming more $\beta$-sheet structures; however, the presence of heparin could also have resulted in more absorption. At $\mathrm{pH} 10$, the Lys-PA again demonstrates a $\beta$-sheet structure; similar to those of the Asp-PA at $\mathrm{pH} 2$ and the Asp-PA with $\mathrm{Ca}^{2+}$ samples. The Asp-PA in solution has $\beta$-sheet structures as well. His-PA without any gelation agent demonstrates $\alpha$-helix and $\beta$ sheet mixture, whereas at $\mathrm{pH} 7$, it has $n \rightarrow \pi^{*}$ transition around $220 \mathrm{~nm}$, indicating the presence of the predominant $\beta$-sheet structure. To observe how time affects the secondary structures of the molecules, 2 month old peptide solutions were also characterized with $\mathrm{CD}$. All aged samples demonstrated some aggregation; The Lys-PA is blue-shifted like the Lys-PA with heparin sample. Asp-PA doesn't show much difference that it has still predominantly $\beta$ sheet characteristic, but less compared to the freshly prepared sample. His-PA didn't change much either. We can conclude that sample aging can result in changes in secondary structure formation, attributed to aggregation.

When the PAs were mixed with oppositely charged ions and molecules, gel formation was observed by naked eye. The gel formation is a sign of a three-dimensional network formed by the extended nanostructures. These nanostructures bundle up and encapsulate water in a cage-like structure and result in gel formation. Therefore, we can conclude that the gel formation is an indirect sign of long nanofiber structure formation. The gel formation 


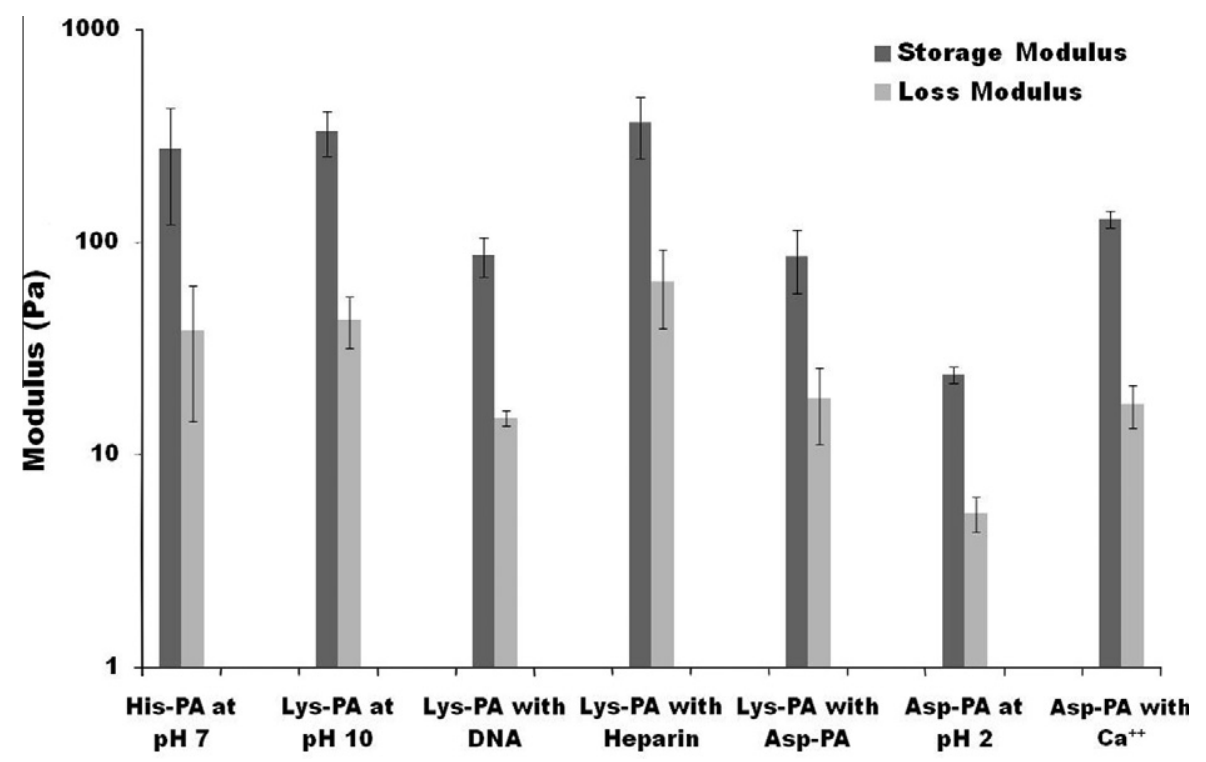

Fig. 7. Oscillatory rheology measurements of the PA gels.

was characterized by oscillatory rheology measurements (Fig. 7). The gelation point is the defining characteristic between a gel and a viscous liquid, at which point the storage modulus $\left(G^{\prime}\right)$ is higher than the loss modulus $\left(G^{\prime \prime}\right)$. The storage moduli of all PA samples were significantly higher than their loss moduli, proving the gel formation upon isolation of the charges triggering the self-assembly process. Three-dimensional scaffolds for tissue engineering should have adequate mechanical strength, which has been shown to affect the growth, differentiation and migration of cells [33]. Tissue elastic moduli start from $0.1 \mathrm{kPa}$ for soft tissues and can reach up to GPas for hard tissues [34]. The Young's moduli of the PA gels shown here are within the range of moduli of elasticity of living tissues.

In this work, three model PA molecules were synthesized to understand the electrostatic interactions in the self-assembled nanofiber formation. All of the molecules were intended to be used at physiological $\mathrm{pH}$, because the aimed hydrocolloid system is designed for cell encapsulation studies. The Lys-PA molecule is positively charged, His-PA molecule is neutral and Asp-PA molecule is negatively charged at $\mathrm{pH}$. The neutralization behaviors $\left(\mathrm{p} K_{\mathrm{a}}\right)$ of the ionizable groups on the amino acids are responsible for the charges on the peptides. These molecules were observed to stay in solution as they are at charged state and found to form self-supporting hydrocolloid gel systems upon isolation of the charges. Although some degree of aggregation of peptides were observed in solution, charge neutralization is required in order to form the network that can encapsulate water for self-supporting gel formation. The aggregation is mainly triggered by hydrophobic collapse because of the alkyl groups and hydrogen bonded $\beta$-sheet structure formation among the peptides. However, the charged groups on the peptides results in some repulsion among the molecules and prevent hydrogen bonding interactions among the peptides. Therefore, a solution form or a viscous solution is usually obtained in the absence of charge isolation. We performed neutralization of the charges by ions or biomacromolecules that are compatible with tissue engineering applications. The positive charge on the Lys-PA was neutralized with an oppositely charged peptide (Asp-PA), a glycosaminoglycan (heparin) and oligonucleotides. These biomacromolecules are selected as model gelator agents that are found in living systems. One can design an injectable Lys-PA solution or a lysine derivative of a bioactive peptide system to form a gel upon contacting with negatively charged biomacromolecules (e.g. carbo- hydrates, proteins, glycosaminoglycans) found in cartilage, cornea, etc. The His-PA molecule can form gel itself at $\mathrm{pH} 7$ without introducing other factors. This gel can be used as a scaffold for many types of tissue regeneration studies. The Asp-PA molecule was designed with negative charges at $\mathrm{pH} 7$ and can interact with positively charged peptides (Lys-PA) and cations (calcium, etc.). Asp-PA molecules can be activated for gels that are useful for mineral rich environments including bone etc. It is important to be able to control the sol-gel transition of the scaffold systems used for cellular therapy. A practical approach should include in situ gel formation upon delivery of the material to the tissue of interest. Therefore, the electrostatic interactions discussed in this study are presenting useful models for potential cell-materials studies.

\section{Conclusion}

In this report, we demonstrated that charge isolation and neutralization for efficient formation of gels composed of self-assembling PAs is important for design and synthesis of the PAs. Three PA molecules with different charges were synthesized to study the effect of charge screening in their self-assembly mechanisms by various characterization methods. PAs self-assemble into nanofibers, which provide useful three-dimensional scaffolds in their gel form for various tissue engineering applications. The PA molecules were observed to aggregate upon neutralization of the charged residues when mixed with oppositely-charged molecules or ions; and the molecules were imaged to determine morphology of the nanostructures. We demonstrated that PA molecules can be designed to self-assemble into nanofibers upon encountering ions and molecules of opposite charge, or can be combined with bioactive molecules like DNA, glycosaminoglycans, and growth factors for self-assembling into biodegradable networks for potential cell encapsulation studies as an extracellular matrix mimicking material. Therefore, electrostatic control of the PA molecules is essential for developing materials that are soluble, thus injectable, until they interact with oppositely-charged molecules in the site of delivery at which point they form gels. Since these PA molecules can be functionalized through addition of bioactive signals which can aid in various physiological processes including cell adhesion, migration and differentiation, such systems will improve the 
regenerative medicine by allowing use of injectable synthetic ECM mimics into defective tissue sites.

\section{Acknowledgments}

This work is supported in part by the Marie Curie IRG Grant 231019, TÜBITAK 110M355 and COMSTECH-TWAS Joint Research Grant. Authors thank to M. Guler for help in TEM and cryo-SEM and Z. Erdogan for help in LC-MS.

\section{Appendix A. Supplementary material}

Supplementary data associated with this article can be found, in the online version, at doi:10.1016/j.jcis.2010.12.076.

\section{References}

[1] R.O. Hynes, Cell 69 (1992) 11.

[2] M.M. Pires, J. Chmielewski, J. Am. Chem. Soc. 131 (2009) 2706.

[3] C.D. Reyes, A.J. García, J. Biomed. Mater. Res., Part A 65A (2003) 511.

[4] J. Heino, Matrix Biol. 19 (2000) 319.

[5] J.B. McCarthy, B. Vachhani, J. Iida, Pept. Sci. 40 (1996) 371

[6] S.D. Blair, C.M. Backhouse, R. Harper, J. Matthews, C.N. McCollum, Br. J. Surg. 75 (1988) 969.

[7] S. Rammelt, T. Illert, S. Bierbaum, D. Scharnweber, H. Zwipp, W. Schneiders, Biomaterials 27 (2006) 5561.

[8] D. Olsen, C. Yang, M. Bodo, R. Chang, S. Leigh, J. Baez, D. Carmichael, M. Perälä, E.-R. Hämäläinen, M. Jarvinen, J. Polarek, Adv. Drug Delivery Rev. 55 (2003) 1547.

[9] L. Cen, W. Liu, L. Cui, W. Zhang, Y. Cao, Pediatr. Res. 63 (2008) 492.

[10] D.Y.S. Chau, R.J. Collighan, M. Griffin, Trends in Biomaterials Research, Nova Science Publishers, New York, 2007.

[11] M. Maeda, S. Tani, A. Sano, K. Fujioka, J. Controlled Release 62 (1999) 313.
[12] K. Kar, P. Amin, M.A. Bryan, A.V. Persikov, A. Mohs, Y.-H. Wang, B. Brodsky, J. Biol. Chem. 281 (2006) 33283.

[13] T. Koide, Philos. Trans. R. Soc. London, B 362 (2007) 1281

[14] C.P. Barnes, S.A. Sell, E.D. Boland, D.G. Simpson, G.L. Bowlin, Adv. Drug Delivery Rev. 59 (2007) 1413.

[15] S. Zhang, M.A. Greenfield, A. Mata, L.C. Palmer, R. Bitton, J.R. Mantei, C. Aparicio, M.O. de la Cruz, S.I. Stupp, Nat. Mater. 9 (2010) 594

[16] A. Aggeli, M. Bell, L.M. Carrick, C.W.G. Fishwick, R. Harding, P.J. Mawer, S.E. Radford, A.E. Strong, N. Boden, J. Am. Chem. Soc. 125 (2003) 9619.

[17] C.L. Shen, R.M. Murphy, Biophys. J. 69 (1995) 640.

[18] B. Ozbas, J. Kretsinger, K. Rajagopal, J.P. Schneider, D.J. Pochan, Macromolecules 37 (2004) 7331.

[19] K.L. Niece, J.D. Hartgerink, J.J.J.M. Donners, S.I. Stupp, J. Am. Chem. Soc. 125 (2003) 7146 .

[20] J.D. Hartgerink, E. Beniash, S.I. Stupp, Science 294 (2001) 1684.

[21] V.M. Tysseling-Mattiace, V. Sahni, K.L. Niece, D. Birch, C. Czeisler, M.G. Fehlings, S.I. Stupp, J.A. Kessler, J. Neurosci. 28 (2008) 3814.

[22] G.A. Silva, C. Czeisler, K.L. Niece, E. Beniash, D.A. Harrington, J.A. Kessler, S.I. Stupp, Science 303 (2004) 1352.

[23] K. Rajangam, H.A. Behanna, M.J. Hui, X. Han, J.F. Hulvat, J.W. Lomasney, S.I. Stupp, Nano Lett. 6 (2006) 2086.

[24] K.M. Galler, A. Cavender, V. Yuwono, H. Dong, S. Shi, G. Schmalz, J.D. Hartgerink, R.N. D'Souza, Tissue Eng. Part A 14 (2008) 2051.

[25] M.J. Webber, J. Tongers, M.-A. Renault, J.G. Roncalli, D.W. Losordo, S.I. Stupp, Acta Biomater. 6 (2010) 3.

[26] M. Ohsaki, T. Okuda, A. Wada, T. Hirayama, T. Niidome, H. Aoyagi, Bioconjugate Chem. 13 (2002) 510.

[27] H.A. Behanna, J.J.J.M. Donners, A.C. Gordon, S.I. Stupp, J. Am. Chem. Soc. 127 (2005) 1193

[28] C. Tang, A.M. Smith, R.F. Collins, R.V. Ulijn, A. Saiani, Langmuir 25 (2009) 9447.

[29] C.N. Pace, G.R. Grimsley, J.M. Scholtz, J. Biol. Chem. 284 (2009) 13285.

[30] J.F. Graveland-Bikker, R. Ipsen, J. Otte, C.G. de Kruif, Langmuir 20 (2004) 6841.

[31] A. Barth, Prog. Biophys. Mol. Biol. 74 (2000) 141.

[32] N.J. Greenfield, TrAC, Trends Anal. Chem. 18 (1999) 236.

[33] D.E. Ingber, L. Dike, L. Hansen, S. Karp, H. Liley, A. Maniotis, H. McNamee, D. Mooney, G. Plopper, J. Sims, N. Wang, in: G. Richard (Ed.), International Review of Cytology, Academic Press, 1994, p. 173.

[34] A.J. Engler, M.A. Griffin, S. Sen, C.G. Bönnemann, H.L. Sweeney, D.E. Discher, J. Cell Biol. 166 (2004) 877. 